\title{
A CONCEPTUAL ANALYSIS OF ANCIENT ECUADORIAN FACES CARVED IN SPONDYLUS SHELLS
}

\author{
Alonso Restrepo de León In memoriam
}

Authors: Alonso Restrepo de León ${ }^{1}$; Hugo Sotomayor ${ }^{2}$; Carolina Sierra ${ }^{3}$; Javier Burgos-Salcedo ${ }^{3}$.

1. Alonso Restrepo de León, Alonso Arte. Bogotá. Colombia. alonsoarte@gmail.com

2. Hugo Sotomayor, Independent Researcher. Bogotá. Colombia. husotri@gmail.com

3. Carolina Sierra. Corporación para la investigacion y la innovación-CIINAS. dcsierrac@corporacionciinas.org Javier Burgos-Salcedo*. Corporación para la investigacion y la innovación -CIINAS. jdburgoss@coorporacionciinas.org

*Corresponding autor: Javier Burgos-Salcedo. jdburgoss@corporacionciinas.org

\begin{abstract}
Shells, probably like no other product of nature, have played an important role in the history of mankind. The pre-Hispanic civilizations of Ibero-America also used certain type of shells profusely in their religious ceremonies, in particular, in Ecuador there were two species of main importance, the Spondylus princeps and the Spondylus calcifer broadly employed to manufacture ornaments that possess a strong symbolic, religious and social meaning and that were almost exclusively used by ruling classes. Among these ornaments, the faces carved on the Spondylus shells are little known. In the present study, we chose a total of fifteen (15) pieces from the Pastor Restrepo Lince's archaeomalacology collection to understand the possible uses of these objects, through the interpretation of the gestures represented on the faces, their dimensions, and their geographical distribution in pre-Hispanic Ecuador. To achieve the proposed objective, we approach the present investigation from the perspective of the formal analysis of concepts, which is a mathematical theory of representation of knowledge, finding that these faces carved in Spondylus, were used daily or in special ceremonial occasions and that its use was common in all the regional cultures of ancient Ecuador, from the oldest such as Valdivia, and for more than 2000 years, indicating a long tradition of the use of Spondylus as an object of great symbolic and economic value until the arrival of the Spanish.
\end{abstract}

Keywords: Spondylus shells; archaeomalacology; archaeozoology; pre-Hispanic Ecuador; knowledge representation; formal concept analysis. 


\section{Introduction}

Shells, probably like no other product of nature, have played an important role in the sometimes as a valuable object of trade or as a material to make everything kind of ornaments, instruments musical or simple household items; and most of the time as a source of aesthetic inspiration to create artistic and architectural works of singular beauty ((Coan, Kabat \& Petit, 2011).

The pre-Hispanic civilizations of Ibero-America also used a certain type of shells profusely in their religious ceremonies. Quetzalcoatl was said to have emerged from the shell of a gastropod. Most of the temples dedicated to this god were richly decorated with shells and their representation seated on a pedestal shaped like them is frequent, as in the temple that was dedicated to him in Teotihuacan, Mexico. However, the oldest American reference is the Spondylus princeps, original of the ancient agro-pottery societies in the villages of Valdivia, on the coast of Ecuador, who developed a propitiatory rite of rains in which this shell was used. The cult was carried to the Ecuadorian Andean south and from there to the Andes of northern Peru, where it became the insignia of a cult of rain, water, and fertility. This spiny shell with ingrown shells was valued as a sacred emblem, but also as a raw material for jewelry and as primitive money.

The Spondylus sp. It is a genus of mollusks of the class Bivalvia, order Pectinida, family Spondylidae. It is a bivalve that lives exclusively in warm marine waters, between 20 and 60 meters deep, generally forming colonies. About a hundred species are known to be scattered in the Antilles, the Indian Ocean, Australia, China, the Philippines, the Pacific Ocean, the West coast of America, the Canary Islands, and the Mediterranean coast. The most important source of extraction is found on the coasts of Ecuador, mainly in the Gulf of Guayaquil, an area of commercial interest for the preColumbian cultures that flourished in Central and South America (Hocquenghem, A.M., 2010).

Of all the Spondylus species, only two are native to the Ecuadorian coasts: Spondylus princeps Broderip, 1883 and Spondylus calcifer Carpenter 1956/7. The most widespread species is Spondylus princeps, also known, in Quechua, as the "mullu" or the Blood of the Gods of the Incas (Museo Arqueológico Rafael Larco Herrera, 1999). Spondylus princeps are characterized by their strong coral red color and the presence of thorns on the external part of the valves. Given its aesthetic and symbolic characteristics, it was used, in ancient rituals, both in its natural form and devoid of its soft parts and reduced to red powder. Its attractive shells found application in the making of jewelry and ceremonial accessories (Martín-Ramos, P. 2001).

The other Spondylus species cited and found at shallower depths than S. princeps is Spondylus calcifer, also known as Oyster, and which is characterized by the red-purple color of the inner band of the valves. The use of this less ostentatious species was limited to the manufacture of pectorals, 
beads for necklaces, and other ornaments. However, until 2017 the use of Spondylus shells for carving faces was practically unknown, some even with complex gestural elements, their characteristics, production techniques, uses, and regional location. It is when Alonso Restrepo de León publishes his book "Los rostros de la mar" (Restrepo de León, 2017), making a detailed technical description of more than 100 pieces of faces carved in S. calcifer and S. princeps all from Ecuador, which are part of the Pastor Restrepo Lince archaeozoology collection.

Our objective in the present study is to understand the possible uses of these objects, through the interpretation of the gestures represented on the faces, their dimensions, and their geographical distribution in pre-Hispanic Ecuador. Also, from an ontological point of view, it is natural to wonder how the different pieces or entities that are part of the collection of the faces carved on Spondylus relate, taking into account their differences or similarities in form, time and place of origin, use, etc., that can characterize each of them. To achieve the proposed objective, we approach the present investigation from the perspective of the formal analysis of concepts, which is a mathematical theory of representation of knowledge (Wille, R. 1982; Wolff, K.E. 1994; Bourdon-García, R; BurgosSalcedo, J. 2016). Briefly, Knowledge representation incorporates findings from psychology (Schank, R \& Abelson, R., 1977) about how humans solve problems and represent knowledge to design formalisms that will make complex systems easier to design and build. It is grounded on an understanding of human thinking based on concepts, which according to the main philosophical tradition, are constituted by its extension, comprising all the objects, in this case, a set of 15 selected Spondylus shells with faces carved on it, which belong to the concept, and its intension, including all attributes or properties of the objects, in this case, the Spondylus species; high, width, location, use; gesture, and frequency of use.

The use of Knowledge Representation, through the Formal Concept Analysis, led us to conclude that these faces carved in Spondylus, used daily or in special ceremonial occasions, and carried exclusively by the high social elites, were common in pre-Hispanic Ecuador in all the regional cultures, from the oldest such as Valdivia, through Machala, Machalilla, Jambelí, and Chorrera, covering more than 2000 years, which indicates a long tradition of the use of Spondylus as an object of great symbolic and economic value in the Andes region and on the coasts of Ecuador. Also, the fact that all the pieces present a clear gesture associated with the face, whether of fear, wisdom, supplication, or power, possibly had the purpose of transmitting a clear message to their ordinary citizens about their status and hierarchy, and also, in the case of the mortuary trousseau, to the powerful gods with whom they hoped to interact on their journey to the underworld. 


\section{Materials and methods}

\section{Archaeological material}

For the present study we chose a total of fifteen (15) pieces from the Pastor Restrepo Lince's archaeomalacology collection, which, according to the criteria of the research group, represented the main characteristics of the collection of faces carved in Spondylus, here named poetically, "Los rostros de la mar" (the faces of the sea). It is worth highlighting the beauty and artistic quality that each of these pieces has (figure 1), which indicates the level of development that this luxury industry reached in pre-Hispanic Ecuador (Restrepo de León, 2017).

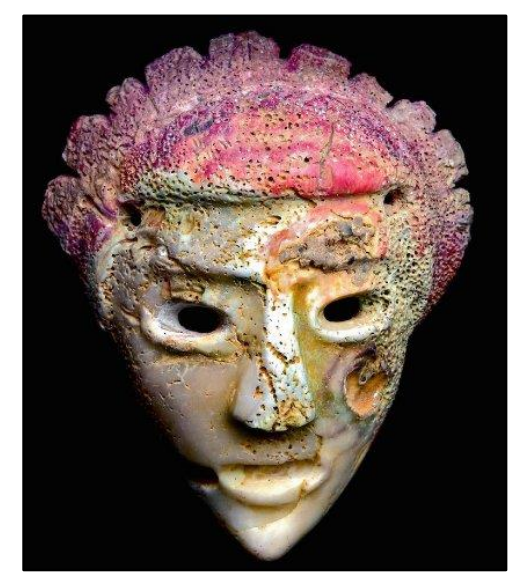

Figure 1. The face and the emotions set in it are pillars of an innate social awareness, a walk towards effective bonding and adaptation to social systems.

Once the pieces were selected, and following Restrepo de León (2017), we proceeded to organize a small data table by writing for each piece, the code of each one, OBJ1 to OBJ15; its corresponding photo; the species of Spondylus in which it was carved; its height and width in centimeters; the place or location where it was found; its use; the gesture, that reflects the face and finally, its frequency of use (Table 1). Regarding gestures, extended workshops were held with experts from different areas of the social and human sciences to carry out its definition (see acknowledgments). 


\begin{tabular}{|c|c|c|c|c|c|c|c|c|c|}
\hline OBJECT No. & FACES & SPECIES & HIGH $(\mathrm{cm})$ & $\begin{array}{l}\text { WITDH } \\
(\mathrm{cm})\end{array}$ & LOCATION & ZONE & USE & GESTURE & FRECUENCY OF USE \\
\hline OBJ1 & & $\begin{array}{l}\text { Spondylus } \\
\text { calcifer }\end{array}$ & 15 & 12,7 & Machala & Jambelí & death mask & astonishment & special occasions \\
\hline OBJ2 & & $\begin{array}{l}\text { Spondylus } \\
\text { princeps }\end{array}$ & 10 & 9 & Puerto López & chorrera & pendant & fuzzy & quotidian \\
\hline OBJ3 & & s. princeps & 10 & 10 & Rocafuerte & machalilla & pendant & power,authority & quotidian \\
\hline OBJ4 & & S. princeps & 10,3 & 10,5 & Puerto viejo & chorrera & pendant & power,authority & quotidian \\
\hline OBJ5 & & s. princeps & 11 & 10,5 & Roca fuerte & machalilla & ritual mask & death & special occasions \\
\hline OBJ6 & & S. calcifer & 12 & 11 & Montecristi & chorrera & cremonial & supplication & quotidian \\
\hline OBJ7 & & S. calcifer & 14 & 14 & Machala & Jambelí & ceremonial & supplication & epacial occasions \\
\hline OBJ8 & & S. calcifer & 18 & 15,3 & Montecristi & chorrera & ceremonial & supplication & special occasions \\
\hline OBJ9 & & S. calcifer & 18 & 15,3 & Puerto López & chorrera & ceremonial & supplication & special occasions \\
\hline OBJ10 & & s. calcifer & 15 & 14 & Puná & Valdivia & ritual mask & death & special occasions \\
\hline OBJ11 & & S. calcifer & 16,5 & 14,5 & puerto López & chorrera & ritual mask & wisdom & special occasions \\
\hline OBJ12 & & S. calcifer & 16,5 & 14 & Puerto López & chorrera & ritual mask & afraid & special occasions \\
\hline OBJ13 & & S. princeps & 13 & 12 & Puerto López & chorrera & ritual mask & death & special occasions \\
\hline OBJ14 & & s. princeps & 13 & 10,3 & Roca fuerte & Chorrera & pendant & power,authority & quotidian \\
\hline OBJ15 & & s. princeps & 11,2 & 10 & roca fuerte & machalilla & pendant & astonishment & quotidian \\
\hline
\end{tabular}

Table 1. Set of faces carved in Spondylus shells used in the present study and their associated basic attributes. Here named "Los rostros de la mar". 


\section{Concept analysis}

Formal concept analysis (FCA) is a mathematical theory oriented, in particular, at applications in knowledge representation, knowledge acquisition, and data analysis. In 1982 R. Wille introduced Formal Concept Analysis as an application of order and lattice theory in connection with so-called Galois connections induced by relations. The theory is based on a set theoretical model for conceptual hierarchies. This model mathematizes the philosophical understanding of a concept as a unit of thoughts consisting of two parts: the extension and the intension (comprehension). The extension covers all objects (or entities) belonging to the concept, while the intension comprises all attributes (or properties) valid for all the objects under consideration. In the present study the objects $(0)$ correspond to the set of all carved shells and their attributes (A) correspond to Spondylus species; high $(\mathrm{cm})$; width $(\mathrm{cm})$; location; use; gesture and frequency of use.

Moreover, $\mathrm{R}(\subseteq 0 \times \mathrm{A})$ is a binary relation between the sets of objects and attributes, respectively. As it is often difficult to list all the objects belonging to a concept and usually impossible to list all its attributes, it is natural to work within a specific context, named formal context, in which the objects and attributes are fixed, here denoted $\mathrm{K}:=(0, \mathrm{~A}, \mathrm{R})$. In formal contexts, which usually refer to some application, the relation $(\mathrm{o}, \mathrm{a}) \in \mathrm{R}$ (often also written as $\mathrm{ORa}$ ) is read as follows: The object $\mathrm{o}$ is in relation $\mathrm{R}$ to the attribute $\mathrm{a}$, if "the object $\mathrm{v}$ has the attribute $\mathrm{a}$ " for example "the face was carved on a Spondylus princeps shell".

A formal context $\mathrm{K}$ can be considered as (the mathematical model of) a table, which relates objects and attributes of a "real situation". The entries in the table indicate by a (x) that the object, the name of which precedes the corresponding row, has the attribute, the name of which is at the top of the corresponding column (of the entry). And by an empty space (blanc: " ") it is expressed that the corresponding object does not have that attribute. Once the formal context $K:=(0, A, R)$ is constructed, a formal concept (of the context $\mathrm{K}$ ) is derived as follows:

If $\mathrm{B} \subseteq \mathrm{O}, \mathrm{D} \subseteq \mathrm{A}$ are arbitrary subsets, then the following derivation operators are defined:

$\mathrm{B}^{\prime}=\{\mathrm{a} \in \mathrm{A} / \mathrm{oRa}$ for all $\mathrm{o} \in \mathrm{B}\}$

$D^{\prime}=\{o \in 0 / o$ Ra for all $a \in D\}$

The pair (B, D) where $B \subseteq 0, D \subseteq A, B^{\prime}=D$ and $D^{\prime}=B$ is called a (formal) concept (of the context $K$ ) with the extent $B$ and intent $D$. To obtain the set of all concepts encoded in the formal context, $a$ central result of Formal Concept Analysis [8] is employed, The Fundamental Theorem on Concept Lattices (Wille, R. 1982) which asserts that given any formal context, it is always possible to obtain a complete lattice that represents it. this complete lattice is called the Concept Lattice of the given context. The proof of the theorem generates an algorithmic procedure that is the basis of the ConExp (java) software (Priss, U. 2005, 2006) to obtain the conceptual Lattice, denoted $\langle\mathbf{B}(\mathrm{O}, \mathrm{A}$, $\mathrm{R}) ; \leq\rangle$ and here named the conceptual lattice of "Los rostros de la mar", of the defined context, in the present case of $K:=(0, A, R)$.

The concept lattice, being a rather universal structure, provides a wealth of information about the relations among objects and attributes, which made possible applications in areas ranging from history and sociology to software engineering and machine learning to e-mail management and 
ontology building. Indeed, it can help in processing a wide class of data types (for example, any data of the carved faces represented as a table).

Finally, apart from structural representation of data, the concept lattice provides a framework in which various data analysis and knowledge acquisition techniques can be formulated, in particular through the notion of attribute implication (Ganter \& Wille, R. 1999). An implication asserts a certain relationship between two attribute sets, called premise and conclusion: an implication is valid in the data set if every object that has all attributes from the premise of the implication also has all attributes from its conclusion. There is a particular implication cover, called the DuquenneGuigues basis (Kuznetsov, S \& Obiedkov, S. 2003), which is proven to have the minimal size among all covers i.e. The set of all valid implications from which all other implications follow semantically. To carry out the Formal Analysis of Concepts for the carved faces in Spondylus spp, the ConExp software (Concept Explorer (Java)) was used, however, today there is an excellent arsenal of free code tools such as Tockit, Galicia, FcaStone, Camelis, Phyton FCA Tool, among others (https://upriss.github.io/fca/fcasoftware.html).

\section{Results}

\section{Formal context}

To construct the formal context $\mathrm{K}:=(0, \mathrm{~A}, \mathrm{R})$, the 15 pieces listed in table 1 are taken as objects, which then make up the set $\mathrm{O}$. The set of attributes $\mathrm{A}$ is defined as follows:

$$
\mathrm{A}=\{\text { species; high; width; location; zone; use; gesture; frequency of use }\}
$$

In turn, sub-attributes are defined for each attribute, forming what is called a multivalued context [], for Spondylus species:

$$
\text { Species }=\{\text { S. calcifer; } \text { S. princeps }\}
$$

Regarding the high of each object, the assigned values, in centimeters, were the following:

$$
\operatorname{High}=\{(9-11) ;(>11-14) ;>14-18)\}
$$

Intervals encompassing the width of the set of 15 objects, are as follows:

$$
\text { width }=\{(9-11) ;(>11-14) ;(>14-16)\}
$$

The set of locations where the pieces were found in Ecuador are presented in equation 5,

Location $=\{$ Machala; Puerto López; Puerto Viejo; Rocafuerte; Montecristi; 
Having defined extension $\mathrm{V}$ and intention $\mathrm{A}$ for the selected shells with carved faces, the formal context $\mathrm{K}:=(\mathrm{O}, \mathrm{A}, \mathrm{R})$ is elaborated according to the proposed methodology and presented in Table 2.

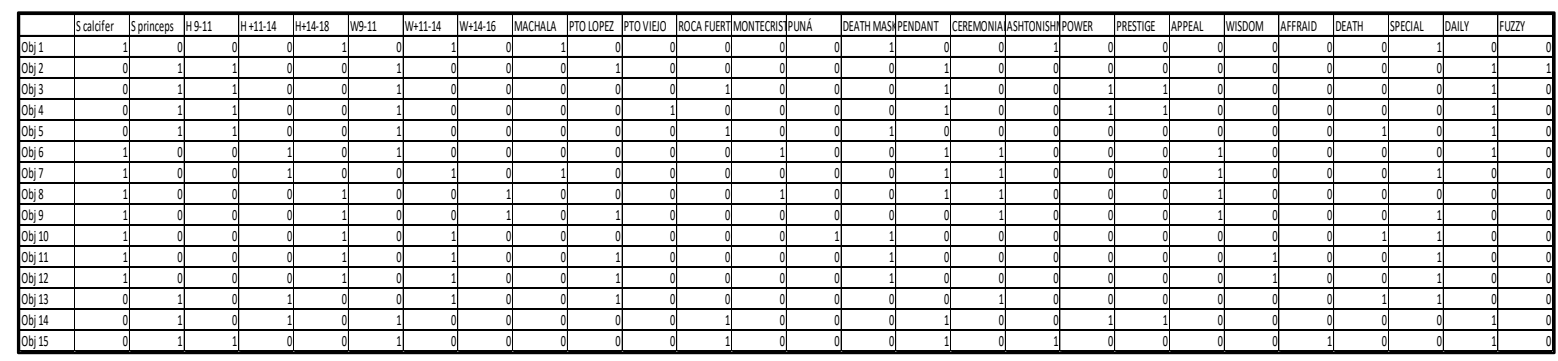

Table 2. The Formal Multivalued Context for Los rostros de la Mar-K: $=(O, A, R)$. For the elaboration of the formal context, 15 carved Spondylus shells (objects) were used and 8 attributes and its values were defined. To each attribute a nominal scale was assigned, whose values were mutually exclusive. The scales and its values (formulas 2-5) were defined based on the review of the published results of Restrepo de León (2017).

Reading the context can be done in a simple way, observing that the ith object has the $j$ th attribute, which is indicated by an $x$ in position ij of the table. By way of example, it can be seen that the OBJ2 has the attribute of represent a fuzzy expression.

\section{Concept Lattices}

As has been mentioned earlier, a concept for this context consists of an ordered pair (B, D), where $\mathrm{B}$ (the extent) is a subset of the 15 objects and $\mathrm{D}$ (the intent) is a subset of the eight attributes with its sub attributes (formulas 1-5). To demand that the concept is determined by its extent and its intent means that $\mathrm{D}$ should contain just those properties shared by all the objects in B, and similarly, the objects in B should be precisely those sharing all the properties or attributes in D (formulas 67). A simple procedure for finding a concept is as follows: take an object, say OBJ2, and let $D$ the set of attributes which it possesses, in this case

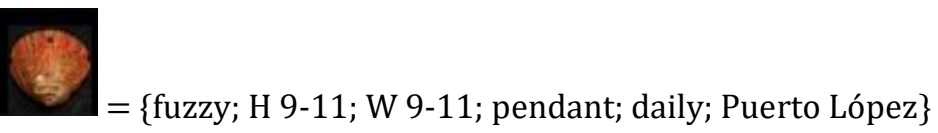

(6)

Then let $B$ the set of all objects possessing all the attributes in $D$, in this case

$$
\mathrm{B}=\{2\}
$$

\footnotetext{
Then $(B, D)=(\{\&\},\{$ fuzzy; H 9-11; W 9-11; pendant; daily; Puerto López $\})$ is a concept, whose complete lattice representation can be seen in figure $\mathbf{2}$.
} 


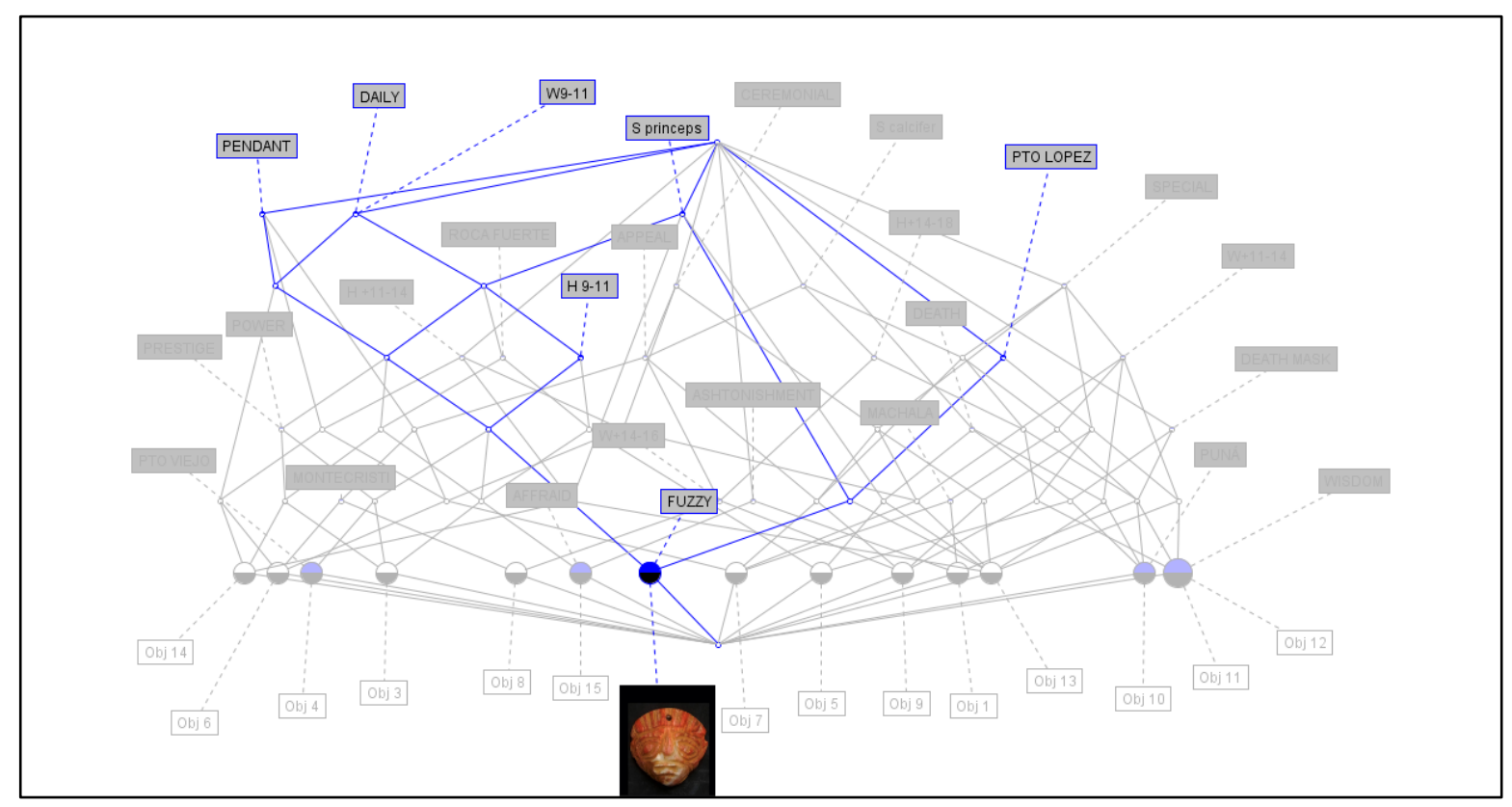

Figure 2. The Concept Lattice of the OBJ2. The black/blue circle represents the concept whose intent can be found by following all line paths going upwards from the circle and noting down the resalted attributes.

The Concept Lattice- $\langle\mathbf{B}(\mathrm{O}, \mathrm{A}, \mathrm{R}) ; \leq\rangle$ of "Los rostros de la mar" (Figure 3), shows the hierarchical structure that are obtained from the context $K:=(0, A, R)$. The Lattice can be read by following the lines that come out of each circle upwards, noting the attributes assigned to each one of them, as already illustrated for the OBJ2. It should be noted that the concept demarcated with the largest black/blue circle contains as an extension two objects, OBJ11 and OBJ12; and its intention corresponds to the following attributes: both of them were carved on shells of the Spondylus calcifer species, these objects possess a gesture that could be interpreted as wisdom, and are large pieces with more than $154 \mathrm{~cm}^{2}$ used as mortuary trousseau and originally found in Puerto López location in Ecuador.

The power of FCA lies in its ability to build a set of logical implications from all the concepts of the context, which constitute the Duquenne-Guiges basis (Kuznetsov, S \& Obiedkov, S. 2003) of the Concept Lattice of "Los rostros de la $\operatorname{mar}^{\prime}-\langle\mathbf{B}(\mathrm{O}, \mathrm{A}, \mathrm{R}) ; \leq\rangle$. Given that the implications, derived by ConExp, are written quite schematically, such as: " $\langle 7\rangle \mathrm{W}$ 9-11 $\Rightarrow$ DAILY", it is necessary to write legibly the set of implications obtained. The implications derived by ConExp have the following format:

$<$ Number of objects $>$ Premise $\Rightarrow$ Conclusion

Number of objects means for how many objects of the context the implication is valid. As an example, and continuing with the previous implication, it is clearer to express it as follows: "seven 
objects with a width in the range between 9 and 11 centimeters are associated with a quotidian use". Thus, incorporated language expressions are necessary for the transformation of the potential mathematical to the actual-logic understanding of the conceptual structures (Wille, R. 1992).

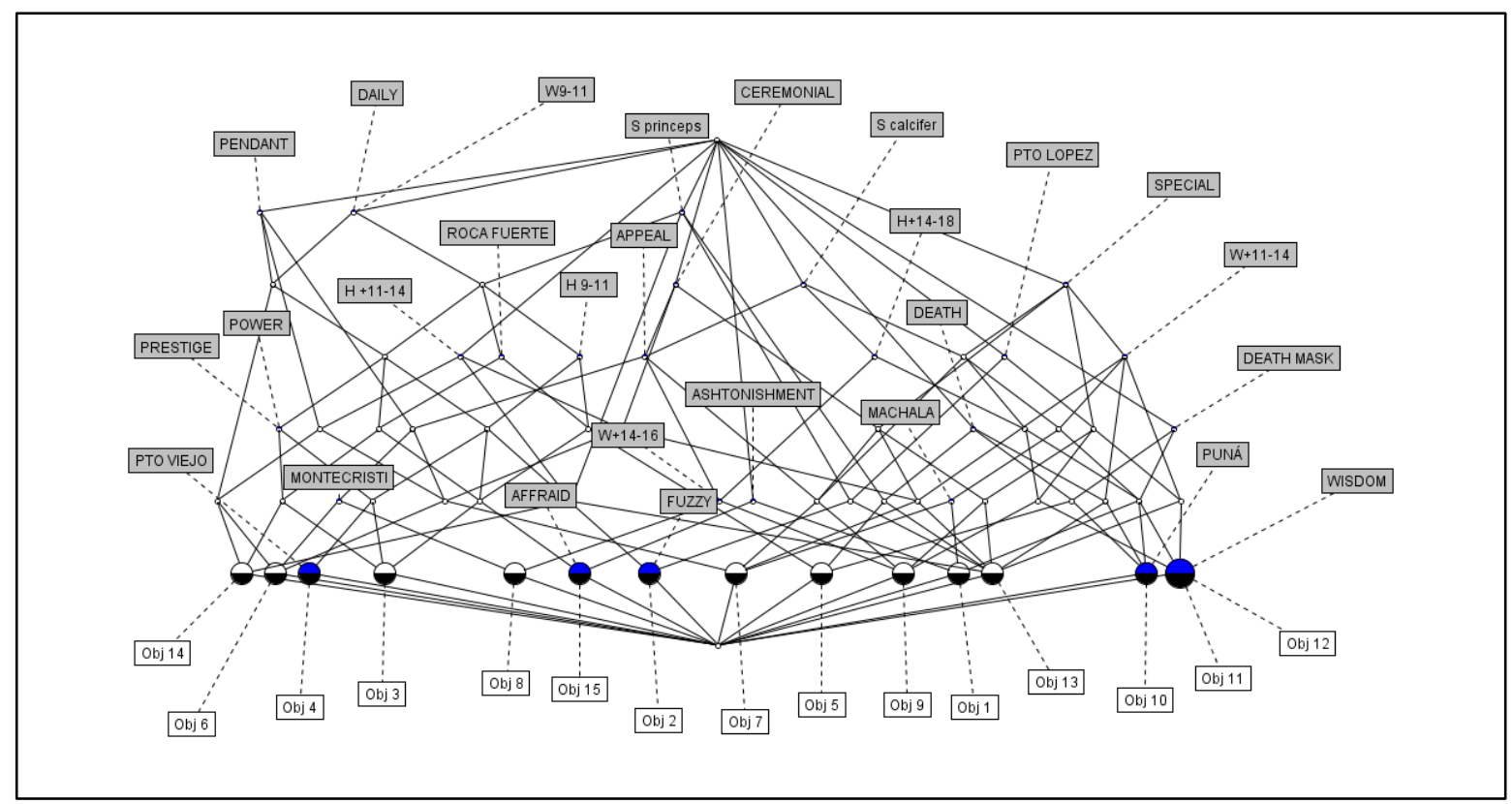

Figure 3. The Concept Lattice of "Los rostros de la mar"- $\{\boldsymbol{B}(O, A, R) ; \leq\rangle$ of the context $K:=(O, A, R)$.

\section{Conclusions and discussion}

From the conceptual analysis of the 15 faces carved in spondylus shells and the review of the specialized literature (López Cuevas, 2005; Martín, 2014; Restrepo de León, 2017) we can reach some interesting conclusions. Regarding the use of Spondylus in the Andes region, it should be noted that in Peru the use of objects made from Spondylus shells is widespread among the dominant classes, represented by necklaces, gutters, and beads usually made with S. princeps. In Ecuador, according to the results of the present study, the use of objects made with spondylus is also restricted to dominant groups such as rulers, priests, or warriors, but unlike Peru, here the shells of S. princeps with faces were used. carved daily, usually as pendants, which were symbols of power, prestige, and hierarchy. López Cuevas (2005) mentions that in Peru the objects made with Spondylus had a high symbolic value, which agrees with our findings, since as regards the larger pieces, usually 132 square centimeters onwards and made in S. calcifer, also highly valued, but less valuable than S. princeps, to be used on special occasions such as funeral ceremonies and religious rituals of prominent figures.

On the other hand, we can conclude that the aforementioned, daily or ceremonial uses were carried out in pre-Hispanic Ecuador by all regional cultures, from the oldest such as Valdivia, through Machala, Machalilla, Jambelí, and Chorrera, covering a period that covers more than 2000 years, which indicates a long tradition of the use of Spondylus as an object of value in the Andes region and on the coasts of Peru and Ecuador. Martin, (2017) mentions a relevant fact that can explain this 
long prevalence in the symbolic use of spondylus and it is its association with a climatic phenomenon of immense importance on the coasts of the South American Pacific such as the El Niño phenomenon. The appearance of spondylus marked the occurrence of a process that had a strong influence on the future of crops, crops, fishing and with it, all the economic activity of the cultures that occupied the region since ancient times and also the commercial exchanges that very actively led to between towns near or linked to the Latin American Pacific Coast and Central America.

Finally, the fact that all the pieces present a clear gesture associated with the face, whether of fear, wisdom, supplication, or power, was unequivocally defined from the elaboration of the object, as well as its possible daily or ceremonial use, which allows us to think that the artisans or artists who made them satisfied the needs, requirements or tastes of the elites who, by using them, wanted to transmit to the people who were under their influence and also, in the case of the mortuary trousseau, to the powerful characters with whom they hoped to interact on their journey to the underworld.

\section{Acknowledgement}

The authors thank the following professionals for their invaluable support for the development of this study: Mónica Puyana, Marine Biologist, Jorge Tadeo Lozano University; Margarita Vargas, Museologist, Universidad de los Andes; Claudia Rojas Sepúlveda, Archaeologist and Paleo pathologist; Rafael Robles, Archaeologist- Museologist-Archaeozoologist and Nicolás Sanín Ordoñez, Professor of Art and Photographer, Sergio Arboleda University. We classify, conserve and protect archaeomalacology objects, pieces carved in bone and stone.

Funding: this research received no external funding.

Conflicts of interest: The authors declare no conflict of interest.

\section{References}

1.Bourdon-García, R; Burgos-Salcedo, J. Formalization of an Environmental Model using Formal concept analysis-FCA. J of Physics Conf. series 2016, 738,1-7.

2. Coan, E.V.; Alan R. Kabat, A.R.; Petit, R.E., 2011. 2,400 years of malacology, 8th ed., February 15, 2011, 936 pp. +42 pp. [Annex of Collations]. American Malacological Society: http://www.malacological.org/publications/2400 malacology.php

3. Ganter, B; Wille, R. Formal concept analysis, Mathematical foundations. Springer-Verlag, Berlin Heidelberg, 1999, 284pp.

4. Hocquenghem, A.M. El Spondylus princeps y la Edad de Bronce en los Andes centrales: Las rutas de intercambios. In producción de bienes de prestigio y ornamentales votivos de la América antigua. Tísoc, E; Reyna, c; González, E. (eds). Syllaba press. 2010. pp. 34-49.

5. https://upriss.github.io/fca/fcasoftware.html 
6. Ifantidis, F; Nikolaidou, M. (eds) Spondylus in Prehistory: New data and approaches. Contributions to the archaeology of shell technologies. 2011.

7. Kuznetsov, S \& Obiedkov, S. Some decision and counting problems of the Duquenne-Guigues basis of implications. Discrete App. Mathematics 2008, 156, 1994-2003.

8. López Cuevas, Fernando. El Spondylus en el Perú prehispánico. Su significación religiosa y económica. Ámbitos. Revista de estudios de ciencias sociales y humanidades. 14: 33-42. 2005.

9. Martín-Ramos, P "En busca del Spondylus. Rutas y Simbolismo", 2001. Disponible en la página web: http://www.scribd.com/doc/13971717/En-Busca-del-Spondylus-Rutas-y-Simbolismo.

10. Museo Arqueológico Rafael Larco Herrera .1999. En torno al Mullu, manjar predilecto de los poderosos inmortales. Spondylus: Ofrenda sagrada y símbolo de paz, pp. 47-102. Fundación Telefónica del Perú, Lima.

11. Priss, U. linguistic Applications of Formal Concept Analysis. In Formal concept analysis foundations and applications. Ganter, B; Stumme, G; Wille, R. (eds) Springer-Verlag Berlin Heidelberg. 2005, pp149-160.

12. Priss, U. Formal concept analysis in Information Science. Ann. Rev. of information Science and Technology 2006, 40, 521-543.

13. Restrepo de León, A. (2017). Los rostros de la mar. https://issuu.com/deadline.stdo/docs/los rostros de la mar 02.compressed

14. Schank, R; Robert Abelson, R. Scripts, Plans, Goals, and Understanding: An Inquiry into Human Knowledge Structures. 1977. Lawrence Erlbaum Associates, Inc. 246pp.

15. Wille, R. Restructuring lattice theory: an approach based on hierarchies of concepts. In I. Rival (Ed.), Ordered sets. Reidel, Dordrecht-Boston, 1982. pp 445-470.

16. Wille, R. Concept lattices and conceptual knowledge systems. Computers \& Mathematics with Applications 1992, 23, 493-515.

17. Wolff, K.E. Conceptual control of complex industrial production processes. Advances in Knowledge Organization 1994, 4, 294. 